\title{
Comparative Genome Analysis of Three Thiocyanate Oxidizing Thioalkalivibrio Species Isolated from Soda Lakes
}

\author{
Tom Berben ${ }^{1}$, Lex Overmars ${ }^{1}$, Dimitry Y. Sorokin ${ }^{2,3}$ and Gerard Muyzer ${ }^{1 *}$ \\ ${ }^{1}$ Microbial Systems Ecology, Department of Aquatic Microbiology, Institute for Biodiversity and Ecosystem Dynamics, \\ University of Amsterdam, Amsterdam, Netherlands, ${ }^{2}$ Winogradsky Institute of Microbiology, Research Centre of \\ Biotechnology, Russian Academy of Sciences, Moscow, Russia, ${ }^{3}$ Department of Biotechnology, Delft University of \\ Technology, Delft, Netherlands
}

Thiocyanate is a $\mathrm{C} 1$ compound containing carbon, nitrogen, and sulfur. It is a (by)product in a number of natural and industrial processes. Because thiocyanate is toxic to many organisms, including humans, its removal from industrial waste streams is an important problem. Although a number of bacteria can use thiocyanate as a nitrogen source, only a few can use it as an electron donor. There are two distinct pathways to use thiocyanate: (i) the "carbonyl sulfide pathway," which has been extensively studied, and (ii) the "cyanate pathway," whose key enzyme,

OPEN ACCESS

Edited by:

Jake Bailey,

University of Minnesota, USA

Reviewed by:

Christiane Dahl,

University of Bonn, Germany

Barbara J. MacGregor,

University of North Carolina at Chapel

Hill, USA

*Correspondence: Gerard Muyzer g.muijzer@uva.nl

Specialty section: This article was submitted to Extreme Microbiology,

a section of the journal

Frontiers in Microbiology

Received: 23 December 2016

Accepted: 07 February 2017

Published: 28 February 2017

Citation:

Berben T, Overmars L, Sorokin DY and Muyzer G (2017) Comparative Genome Analysis of Three Thiocyanate Oxidizing Thioalkalivibrio Species Isolated from Soda Lakes.

Front. Microbiol. 8:254.

doi: 10.3389/fmicb.2017.00254 thiocyanate dehydrogenase, was recently purified and studied. Three species of Thioalkalivibrio, a group of haloalkaliphilic sulfur-oxidizing bacteria isolated from soda lakes, have been described as thiocyanate oxidizers: (i) Thioalkalivibrio paradoxus ("cyanate pathway"), (ii) Thioalkalivibrio thiocyanoxidans ("cyanate pathway") and (iii) Thioalkalivibrio thiocyanodenitrificans ("carbonyl sulfide pathway"). In this study we provide a comparative genome analysis of these described thiocyanate oxidizers, with genomes ranging in size from 2.5 to 3.8 million base pairs. While focusing on thiocyanate degradation, we also analyzed the differences in sulfur, carbon, and nitrogen metabolism. We found that the thiocyanate dehydrogenase gene is present in 10 different Thioalkalivibrio strains, in two distinct genomic contexts/genotypes. The first genotype is defined by having genes for flavocytochrome $c$ sulfide dehydrogenase upstream from the thiocyanate dehydrogenase operon (present in two strains including the type strain of TV. paradoxus), whereas in the second genotype these genes are located downstream, together with two additional genes of unknown function (present in eight strains, including the type strains of TV. thiocyanoxidans). Additionally, we found differences in the presence/absence of genes for various sulfur oxidation pathways, such as sulfide:quinone oxidoreductase, dissimilatory sulfite reductase, and sulfite dehydrogenase. One strain (TV. thiocyanodenitrificans) lacks genes encoding a carbon concentrating mechanism and none of the investigated genomes were shown to contain known bicarbonate transporters. This study gives insight into the genomic variation of thiocyanate oxidizing bacteria and may lead to improvements in the application of these organisms in the bioremediation of industrial waste streams.

Keywords: chemolithoautotrophs, thiocyanate, Thioalkalivibrio, soda lakes, thiocyanate dehydrogenase 


\section{INTRODUCTION}

Thiocyanate is a pseudohalide $\mathrm{C} 1$ compound consisting of carbon, nitrogen, and sulfur. Natural sources include the process of cyanide detoxification, in which rhodanese (thiosulfate:cyanide sulfurtransferase, EC 2.8.1.1) catalyzes the transfer of the sulfane sulfur of thiosulfate to cyanide (Cipollone et al., 2007), and the breakdown of glucosinolatecontaining plants, mostly members of the order Brassicales (Lee and Kwon, 2015). When cells of these plants are damaged, glucosinolates are hydrolyzed by myrosinase (thioglucosidase, EC 3.2.1.147) to form organic (iso)thiocyanates and organic nitriles, which are then further metabolized to form free thiocyanate (Lee and Kwon, 2015). In industry, it is found for example in gold and silver mine tailings, where cyanide is commonly used as a lixiviant, or in coking plant effluent (Gould et al., 2012). Thiocyanate is toxic to humans, inhibiting uptake of iodine by the thyroid gland (Brauer et al., 2006), and to numerous insects and aquatic organisms (Bhunia et al., 2000). Due to this toxicity, the removal of thiocyanate from industrial waste streams is an important process. Bioremediation has been suggested as an efficient and low-cost alternative to chemical destruction (Gould et al., 2012) and a number of applications have been devised and studied (Huddy et al., 2015; Kantor et al., 2015; reviewed in Watts and Moreau, 2016). This includes the coupling of lithotrophic thiocyanate degradation to algal lipid production (Ryu et al., 2014), transforming a waste stream into a potential product stream.

A number of bacterial species have been described with the ability to use thiocyanate for growth. Heterotrophic bacteria belonging to the genera Klebsiella (Lee et al., 2003), Sphingomonas, Ralstonia (du Plessis et al., 2001), Methylobacterium (Wood et al., 1998), and Arthrobacter (Betts et al., 1979) are capable of growth with thiocyanate as a nitrogen source. However, growth with thiocyanate as an electron donor is only possible for a small number of autotrophic sulfuroxidizing bacteria: Thiobacillus thioparus (Katayama et al., 1998), Tb. denitrificans (Kelly and Wood, 2000), and Paracoccus thiocyanatus (Katayama et al., 1995) are all neutrophiles. Among extremophiles, there are the halophilic species Thiohalophilus thiocyanoxidans (Sorokin et al., 2007), and Thiohalobacter thiocyanaticus (Sorokin et al., 2010), Halothiobacillus sp. (Sorokin et al., 2014a) and the haloalkaliphilic species Thioalkalivibrio paradoxus, Tv. thiocyanoxidans (Sorokin et al., 2002) and Tv. thiocyanodenitrificans (Sorokin et al., 2004). There are two known enzymatic pathways for the primary degradation of thiocyanate (Sorokin et al., 2001b): the "COS pathway" and the "cyanate pathway." The former involves hydrolysis of the $\mathrm{C} \equiv \mathrm{N}$ bond by thiocyanate hydrolase (EC 3.5.5.8) to form carbonyl sulfide (COS) and ammonia. The COS is then further hydrolysed by COS hydrolase to sulfide, which enters the common sulfur oxidation pathway, and carbon dioxide. The latter pathway involves direct oxidation of the sulfane atom by $\mathrm{TcDH}(\mathrm{TcDH}$; thiocyanate:cytochrome $c$ oxidoreductase), forming cyanate and elemental sulfur. The $\mathrm{TcDH}$ has recently been purified from $T$ v. thiocyanooxidans and Tv. paradoxus and fully characterized (Tsallagov et al., 2015).

The genomes of a large number of Thioalkalivibrio isolates, including the three known thiocyanate-utilizing species, were sequenced, assembled and annotated at the US Department of Energy by the Joint Genome Institute as part of its Community Science Program. It is the only genus of which multiple thiocyanate-oxidizing strains have been sequenced; the only other publicly available genome belongs to $T b$. thioparus DSM 505, which uses the "COS pathway" (GenBank NZ_ARDU0000 0000.1).

Thioalkalivibrio is a group of chemolithoautotrophic, obligately haloalkaliphilic Gammaproteobacteria within the family Ectothiorhodospiraceae. Thioalkalivibrio are found in saline alkaline lakes occurring mostly in arid regions around the world, such as the Central Asian Great Steppes in southern Siberia, Mongolia and China, in the rain-shadowed areas of California and Nevada, Wadi Natrun in Egypt and the East African Rift Valley (Sorokin et al., 2014b). Soda lakes are characterized by a high $\mathrm{pH}$ (9-11) and moderate to high salinity, up to saturation. The dominant salts in solution are sodium carbonate/bicarbonate and $\mathrm{NaCl}$, leading to a stable alkaline buffered system (Grant and Sorokin, 2011). Members of the genus Thioalkalivibrio are capable of oxidizing a variety of reduced, inorganic sulfur compounds, such as sulfide, polysulfides, thiosulfate, elemental sulfur, sulfite, and polythionates (Sorokin et al., 2001a). Three species can also use thiocyanate as an electron donor. Tv. thiocyanoxidans is a small motile vibrio and some strains (including type strain $\mathrm{ARh} 2^{\mathrm{T}}$ ) are capable of growth in saturated soda brines (up to $4.3 \mathrm{M} \mathrm{Na}^{+}$) (Sorokin et al., 2002). The moderately salt-tolerant $T v$. paradoxus is a large, non-motile rod and, in contrast to other members of the Ectothiorhodospiraceae, stores the elemental sulfur globules that are an intermediate of sulfide/thiosulfate/thiocyanate oxidation intracellularly (Sorokin et al., 2002). Tv. thiocyanodenitrificans is moderately salt-tolerant, the cells are motile rods and it is capable of anaerobic growth by denitrification with either thiosulfate or thiocyanate as electron donor (Sorokin et al., 2004). So far, genomic analysis of Thioalkalivibrio has been limited to Tv. sulfidophilus HL-EbGr7 and Thioalkalivbrio sp. K90mix (Muyzer et al., 2011a,b), two species not capable of metabolizing thiocyanate. Recently, the genome of Tv. versutus D301 was published (Mu et al., 2016), though it is unknown whether this strain is able to oxidize thiocyanate.

Here, we present a comprehensive comparative analysis of the genomes belonging to the type strains of thiocyanateoxidizing Thioalkalivibrio species Tv. paradoxus ARh $1^{\mathrm{T}}, T v$. thiocyanoxidans $\mathrm{ARh} 2^{\mathrm{T}}$ and Tv. thiocyanodenitrificans $\mathrm{ARhD}$ $1^{\mathrm{T}}$. The main focus of the analysis was on thiocyanate degradation, as well as on core sulfur, carbon, and nitrogen metabolism, and genes involved in adaptation to haloalkaline environments. A comprehensive analysis of these genomes will add to our understanding of thiocyanate degradation both in natural systems, such as soda lakes, as well as in industrial applications. 


\section{MATERIALS AND METHODS}

\section{Sequencing and Annotation}

Sequencing and annotation procedures were described in detail elsewhere (Berben et al., 2015a,b,c). Basic genome properties are summarized in Table 1. Tv. paradoxus (GenBank accession CP007029.1) is a finished-quality genome consisting of $3,756,729$ bp with a GC-content of $66.6 \%$, whereas Tv. thiocyanoxidans (GenBank accession ARQK00000000.1) and Tv. thiocyanodenitrificans (GenBank accession AQZO00000000.1) are in permanent draft status. The genome for Tv. thiocyanoxidans contains 2,765,337 bp in 61 scaffolds, with a GC-content of $66.2 \%$. The Tv. thiocyanodenitrificans genome consists of $3,746,647 \mathrm{bp}$ in three scaffolds, with a GC-content of $64.8 \%$.

\section{General Analysis}

Pairwise synteny was calculated for all pairs of genomes using the software SyMAP v4.2 (Soderlund et al., 2006) with default settings. Synteny blocks were exported from the program in tab-separated value format for further processing. BioPython 1.63 (Cock et al., 2009) (with Python 2.7.6) was used to calculate GC skew in all three genomes. Genomic islands in the Tv. thiocyanodenitrificans genome were identified by the program IslandViewer (Langille and Brinkman, 2009). Raw reads were aligned to the available assembly using Bowtie 2.1.0 (Langmead and Salzberg, 2012), the output was converted to BAM format, sorted and indexed using Samtools 0.1.19 (Li et al., 2009) and visualized in the Integrative Genomics Viewer 2.3.18 (Thorvaldsdóttir et al., 2013). Additionally, CheckM 0.9.7 (Parks et al., 2014) was used to assess the completeness and heterogeneity of the genomes. Visualization of the synteny, GC skew and genomic islands was accomplished using Circos 0.64 (Krzywinski et al., 2009).

\section{Detection of Specific Genes and Gene Clusters}

The Basic Local Alignment Search Tool (BLAST) (Altschul et al., 1990) was used to align sequences of reference proteins to the genomes. Reviewed reference sequences were taken from UniProt $^{1}$ database if available; otherwise non-curated sequences from TrEMBL were used instead. In case sequences from multiple organisms were available, the most closely related organism was

${ }^{1}$ www.uniprot.org

TABLE 1 | Overview statistics for the genomes of Tv. paradoxus, Tv. Thiocyanodenitrificans, and Tv. thiocyanoxidans.

\begin{tabular}{lcccc}
\hline Species & $\begin{array}{c}\text { Genome } \\
\text { size (Mbp) }\end{array}$ & Scaffolds & \% GC & $\begin{array}{c}\text { Protein } \\
\text { coding genes }\end{array}$ \\
\hline $\begin{array}{l}\text { TV. paradoxus ARh 1 } \\
\text { T }\end{array}$ & 3.8 & 1 & 66.6 & 3,557 \\
$\begin{array}{l}\text { TV. thiocyanodenitrificans } \\
\text { ARhD 1 }\end{array}$ & 3.7 & 3 & 64.8 & 3,558 \\
$\begin{array}{l}\text { TV. thiocyanoxidans } \\
\text { TRh } 2^{\top}\end{array}$ & 2.5 & 61 & 66.18 & 2,677
\end{tabular}

chosen. The best hit in BLAST was used, if the query coverage exceeded $75 \%$ and the identity was higher than $30 \%$. When a cluster of genes was expected, but no BLAST hits meeting the threshold were generated, the gene context of the cluster was inspected using the gene cassette search tool in IMG (Markowitz et al., 2014), which allowed for the detection of genes present, but below threshold. All reference sequences used, together with BLAST results for all strains studied here are available in the Supplementary Table S1.

\section{Phylogenetic Analyses}

To determine the type of $\mathrm{RuBisCO}$, sequences of the large subunit were taken from (Tabita et al., 2007) and aligned using Clustal Omega (Sievers et al., 2011). The optimal amino acid substitution model was determined using MEGA6 (Tamura et al., 2013) and phylogenetic trees were calculated with maximum likelihood. Statistical support for tree nodes was calculated with 500 bootstrap iterations. Sequences for the $d s r \mathrm{AB}$ tree were taken from Loy et al. (2009). This tree was constructed following the same procedure as described for $\mathrm{RuBisCO}$. The trees were visualized using Figtree 1.4.2 2 .

\section{RESULTS AND DISCUSSION}

\section{General Genome Features}

The genome of Tv. paradoxus has been fully resolved and comprises approximately $3.7 \mathrm{Mbp}$. The genome of $\mathrm{Tv}$. thiocyanodenitrificans consists of three scaffolds with a total size of $3.7 \mathrm{Mbp}$, of which the largest scaffold contains $90 \%$ of the sequence. The Tv. thiocyanoxidans sequence is divided over 61 contigs that remain unordered. Syntenic regions between Tv. paradoxus and Tv. thiocyanodenitrificans were apparent, with synteny blocks as large as $500 \mathrm{Kbp}$ (Figure 1). The calculation of synteny between $T v$. thiocyanoxidans and the other genomes is difficult, due to the limits imposed by contig sizes. Likely, this plot underrepresents the similarities between Tv. thiocyanoxidans and the other two genomes. Despite this, there are significant portions of sequence on all three genomes that are not conserved, including several complete contigs of Tv. thiocyanoxidans. The $300 \mathrm{Kbp}$ scaffold of Tv. thiocyanodenitrificans has no synteny with either of the other genomes, whereas the second largest non-syntenic area is approximately $150 \mathrm{Kbp}$ big. Upon closer inspection, this scaffold was revealed to contain 37 tRNA genes (comprising all 20 types) and two transposases; the rest of the gene products were annotated as hypothetical proteins. A complete set of tRNA genes is also present in the $3.4 \mathrm{Mbp}$ scaffold. This scaffold has an average coverage of about $6,000 \mathrm{x}$ and few single nucleotide polymorphisms (SNPs), whereas the $300 \mathrm{Kbp}$ scaffold has a coverage of 4,000x and shows a higher occurrence of SNPs. The origin of the two smaller scaffolds (300 and $30 \mathrm{Kbp}$, respectively) remains a question. The fact that they have no synteny with any of the other Thioalkalivibrio genomes indicates a possible contamination in the sequenced DNA. We performed a quality control step using

\footnotetext{
${ }^{2}$ http://tree.bio.ed.ac.uk/software/figtree/
} 


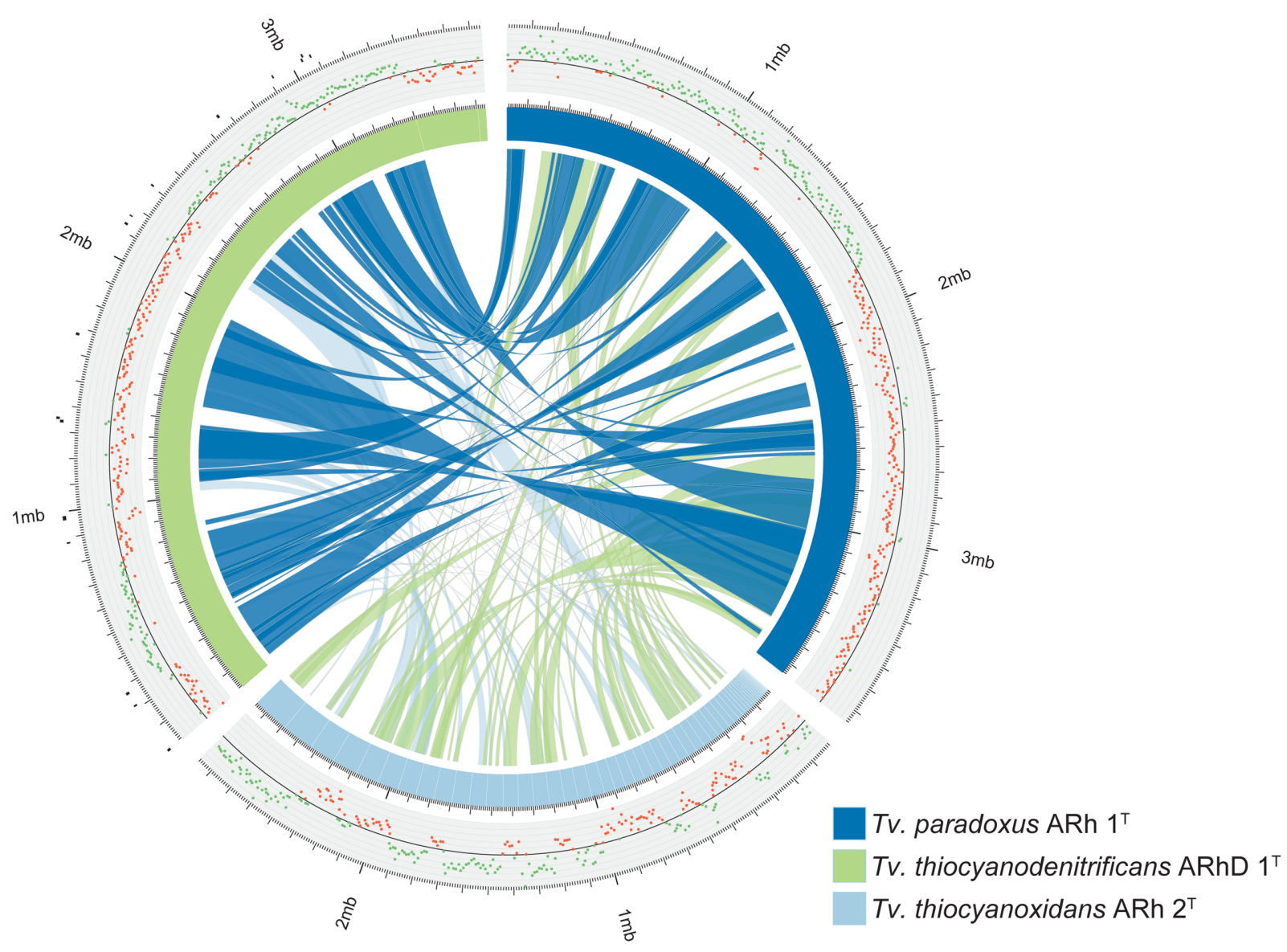

FIGURE 1 | Overview of the genomes of Tv. paradoxus, Tv. thiocyanoxidans, and Tv. thiocyanodenitrificans. The blue and green segments represent the chromosomes, with white lines marking the contig boundaries. The inner ribbons connect pairwise synteny blocks, with wider ribbons denoting larger blocks. The plot outside the chromosome ring shows the GC-skew, the green and red dots denote positive and negative skew, respectively. The black markers outside the TV. thiocyanodenitrificans chromosome indicate putative genomic islands, as predicted by IslandViewer.

TABLE 2 | Overview of CheckM results.

\begin{tabular}{|c|c|c|c|c|}
\hline Species & Scaffolds & Completeness & Contamination & Strain heterogeneity \\
\hline Tv. thiocyanodenitrificans ARhD $1^{\top}$ & All & 99.94 & 2.26 & 40 \\
\hline Tv. thiocyanoxidans ARh $2^{\top}$ & All & 99.94 & 0.34 & 0 \\
\hline
\end{tabular}

CheckM (Parks et al., 2014) was used to estimate the completeness, strain heterogeneity and level of contamination. For Tv. thiocyanodenitrificans, there is an entry for the three scaffolds together as well as one for the largest scaffold (3.4 Mbp) alone.

CheckM (Parks et al., 2014), comparing the results for all three scaffolds combined vs. only the $3.4 \mathrm{Mbp}$ scaffold. The results are summarized in Table 2. The CheckM analysis supports the reliability of scaffold one, as strain completeness (99.94\%) does not decrease when scaffolds two and three are removed, whereas strain heterogeneity and contamination scores are significantly lower ( 0 vs. $40 \%$ and 1.03 vs. $2.26 \%$, respectively). The strain completeness further shows that the main 3.4 Mbp scaffold has a (nearly) complete set of conserved marker genes. Given the information on the Tv. thiocyanodenitrificans sequence provided by the coverage and the CheckM analysis, only the largest scaffold (3.4 Mbp, scaffold 1) was used for further analysis.

GC-skew provides an unambiguous estimate for the location of the origin of replication in Tv. paradoxus. The GC-skew of the $T v$. thiocyanodenitrificans genome contains three sign changes. IslandViewer was used to predict genomic islands in this genome. The putative islands are small (Figure 1), but one is located in close proximity to the skew sign change at $250 \mathrm{Kbp}$. A transposase can indeed be found in the vicinity of this region. $d n a A$ is located in the vicinity of the sign change at $2.3 \mathrm{Mbp}$. This suggests that the origin of replication should be located near this position. 


\section{Thiocyanate Metabolism}

The first description of thiocyanate dehydrogenase activity was provided by Sorokin et al. (2001b) who showed its presence and activity in the soluble fraction of lysed cells of Tv. paradoxus ARh 1 and Thioalkalivibrio sp. ARh 4. The degradation of thiocyanate by these bacteria correlated with the presence of a band at approximately $50 \mathrm{kDa}$ after gel electrophoresis of total protein extracts (Sorokin et al., 2001b). The structure and sequence of $\mathrm{TcDH}$, purified from $T v$. paradoxus and $T v$. thiocyanoxidans, were determined (Tsallagov et al., 2015) and this data has recently been released in the Protein Data Bank (PDB) under PDB IDs 5F75 (Tv. paradoxus) and 5F30 (Tv. thiocyanoxidans). The elucidation of the amino acid sequence of $\mathrm{TcDH}$ has enabled a search for the corresponding gene in all genomes that are currently available. TcDH is present in the two known cyanate pathway-utilizing Thioalkalivibrio, and its exact match is also present in eight genomes belonging to other Thioalkalivibrio strains not previously reported to be capable of thiocyanate oxidation. In contrast, no closely related genes can be found in any other publically available genomes in GenBank. The closest are two proteins with unknown function in the (meta)genomes of Thioploca ingrica and Hydrogenobacter thermophilus. The gene encoding TcDH is located in two different types of gene clusters, as shown in Figure 2. In Tv. paradoxus ARh $1^{\mathrm{T}}$ and Tv. nitratireducens ALEN $2^{\mathrm{T}}$ [which form a separate phylogenetic cluster within the genus Thioalkalivibrio (Tourova et al., 2007)] TcDH is followed downstream by four ABC-type transporter subunits (two permease and two ATP-binding), two hypothetical proteins and two genes annotated as a putative two-component regulatory system with a $\sigma^{54}$ responsive element. In ALEN $2^{\mathrm{T}}, T c D H$ is flanked upstream by an additional gene of unknown function. On the opposite strand this cluster is flanked downstream by three genes coding for both subunits of flavocytochrome $c$ sulfide dehydrogenase $(f c c \mathrm{AB})$ and a small $c$-type cytochrome, and upstream by copper resistance genes $\operatorname{cop} \mathrm{CD}$, twin-arginine transporter system subunit tat $\mathrm{A}$, and a gene annotated as multiple antibiotics resistance system $y c h \mathrm{E}$. The latter is actually more similar to the Escherichia coli gene marC, whose function is currently unknown (McDermott et al., 2008). The second type of cluster is present in the second, major group of the TcDHpositive Thioalkalivibrio, including in Tv. thiocyanoxidans ARh $2^{\mathrm{T}} / 3 / 4 / 5$; Tv. nitratis ALJ4/5, AL5 and Thioalkalivibrio sp. AKL 11. Similar to the first, $T c D H$ is followed downstream by four $\mathrm{ABC}$ transporter subunits, two genes of unknown function (one in the Tv. thiocyanoxidans strains) and a putative $\sigma^{54}$ responsive two-component regulator. On the opposite strand this operon is flanked downstream only by a small $c$-type cytochrome and upstream by $\operatorname{cop} \mathrm{CD}, \operatorname{tat} \mathrm{A}, f c c \mathrm{AB}$, a gene coding for an iron complex outer membrane receptor protein, and a bacterial neuraminidase (BNR) domain-containing protein. In Thioalkalivibrio sp. AKL 11, the latter two genes are missing. The flavocytochrome $c$ genes are instead followed by genes encoding a transposase and an integrase core domain containing protein. Interestingly, strain AKL 11 was the most difficult of all TcDH-positive ones to adapt to growth on thiocyanate. These three groups of gene clustering also correspond to the three subgroups of protein homology of TcDH itself (Tsallagov et al., 2015).

$\mathrm{TcDH}$ is only active when it binds copper as a cofactor (Tsallagov et al., 2015), which might explain the presence of $\operatorname{cop} \mathrm{CD}$ in the cluster. The twin-arginine transporter (tat) system transports folded proteins, including cofactors, across the cytoplasmic membrane. $\mathrm{TcDH}$ contains the C-terminal tat signal peptide [ST]-R-R-x-F-L-K, starting at amino acid position 34 (S-R-R-K-F-L-K), conserved for all 11 sequences known presently. The flavocytochrome $c$ sulfide dehydrogenase participates in sulfide oxidation and the small $c$-type cytochrome possibly participates in the final stage of electron transport. The function of the ABC-type transporter might be in copper acquisition, while the role of the BNR-repeat containing gene and the iron outer membrane complex are currently unknown.

The genomic information on the COS pathway of thiocyanate oxidation is limited to two species: Tb. thioparus DSM $505^{\mathrm{T}}$ and Tv. thiocyanodenitrificans $\mathrm{ARhD} 1^{\mathrm{T}}$, as shown in Figure 3. In Thiobacillus, the three genes for thiocyanate hydrolase ( $\operatorname{scn} \mathrm{ABC})$ are followed downstream by a hypothetical protein, four subunits of a NitT/TauT family ABC-type transporter (with another hypothetical protein between the third and fourth gene), a peroxiredoxin (a DsrE/F-like protein, often works in concert with TusA), a tusA-related sulfur transferase (which might be involved in elemental sulfur oxidation), sulfide:quinone oxidoreductase (which oxidizes sulfide), and finally another hypothetical protein. Genes for a cyanase, a methylase and a single ABC-type cobalt transporter subunit are found upstream of thiocyanate hydrolase. The presence of cyanase has also been found biochemically in another recently described SOB oxidizing thiocyanate via the COS pathway - Thiohalophilus thiocyanoxidans (Bezsudnova et al., 2007). This once again highlights that the early identification of the "cyanate pathway" on the basis of the presence of cyanase activity (Youatt, 1954) is not valid.

\section{Sulfur Metabolism}

The dissimilatory sulfur cycle is a complex network of red-ox reactions and intermediates, with many different enzymes involved in biological sulfur transformations. Figure 4 shows a schematic overview of sulfur oxidation reactions in the Thioalkalivibrio species studied here, showing the presence or absence of enzymes per species.

Oxidation of sulfide is mediated by either flavocytochrome $c(f c c \mathrm{AB})$ or sulfide:quinone reductase $(s q r)$, both of which produce polysulfide. In all three Thioalkalivibrio genomes, $f_{c c} \mathrm{AB}$ is detected, whereas $s q r$ is detected only in $T v$. thiocyanodenitrificans (52\% identity at the amino acid level to Acidithiobacillus ferrooxidans) and with low sequence similarity in Tv. paradoxus (25\% identity in amino acid sequence). In gammaproteobacterial sulfur-oxidizing chemolithotrophs, thiosulfate is usually oxidized to sulfur by a truncated Sox system, consisting of soxXAYZB, that lacks sox $\mathrm{CD}$ (Ghosh and Dam, 2009). This truncated system was also found in the genomes of all three thiocyanate-oxidizing Thioalkalivibrio species. From zero-valent sulfur, there are two pathways to sulfate, i.e., (i) a direct reaction in which sox CD performs a six-electron oxidation 

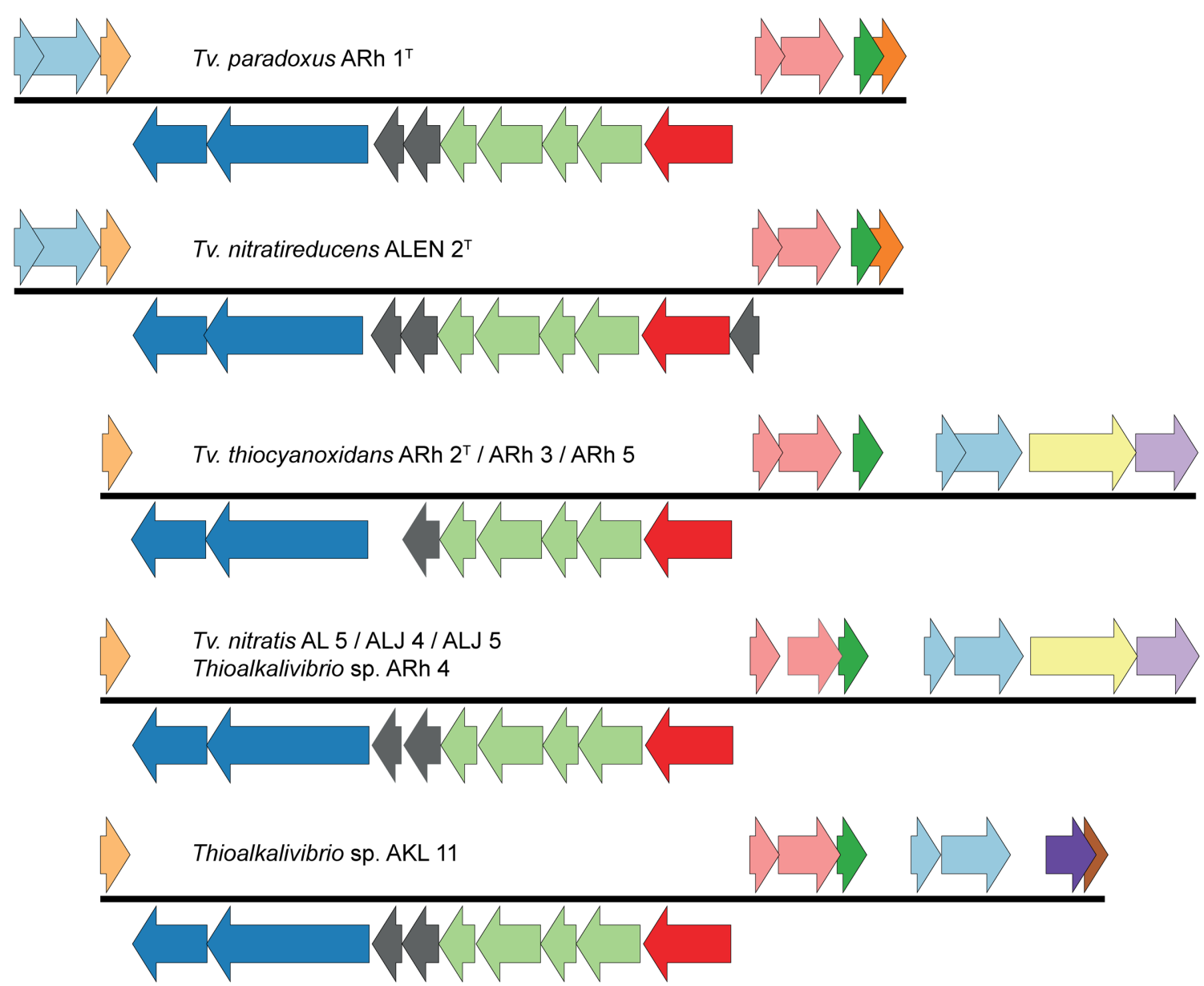

\footnotetext{
Thiocyanate dehydrogenase

Flavocytochrome $c$ (flavo/cyt subunits)

Cytochrome $c$ type enzyme

Transposase ins $\mathrm{O}$ and inactivated derivatives

Integrase core domain containing protein

ychE multiple antibiotics resistance system
}

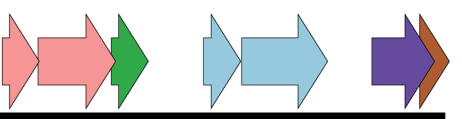

FIGURE 2 | Genomic context of the TcDH gene in all Thioalkalivibrio species in which it is present. There are two main genotypes, defined primarily by the location of genes for flavocytochrome $c$ sulfide dehydrogenase and the presence/absence of an iron outer membrane complex gene and a bacterial neuraminidase (BNR) gene. A third genotype is formed by the insertion of a transposase in Thioalkalivibrio sp. AKL 11. The IMG locus tags for the genes shown here are: ARh 1, Thith2703-2718; ALEN 2, TVNIR_2749-2765; ARh 2, G372DRAFT_01361-01376; ARh 3, C995DRAFT_1535-1550; ARh 5, G331DRAFT_0046-0061; AL 5, F574DRAFT_2579-2595; ALJ 4, C936DRAFT_2816-2832; ALJ 5, C937DRAFT_2833-2849; ARh 4, F465DRAFT_2655-2671; AKL 11, D574DRAFT_00079-00095.

and (ii) a pathway where sulfur is oxidized to sulfite by the dissimilatory sulfite reductase pathway acting in reverse. The dsrABEFHCMKLJOPNR cluster was found in Tv. paradoxus and Tv. thiocyanodenitrificans, with $d s r S$ located elsewhere in the genome (Figure 5A). Figure 5B shows a phylogenetic analysis of concatenated $d s r \mathrm{AB}$ amino acid sequences. This analysis clearly shows that the $d s r$ genes in these Thioalkalivibrio species belong to the clade of $\mathrm{rdsr} \mathrm{AB}$ proteins with known sulfur-oxidizing activity (Loy et al., 2009). Tv. thiocyanoxidans, similar to Thioalkalivibrio sp. K90mix, lacks both the $d s r$ cluster and soxCD (Muyzer et al., 2011b). From sulfite there is a direct pathway to sulfate via a two-electron transfer mediated by sulfite:cytochrome $c$ oxidoreductase (Kappler and Dahl, 2001), which was only found in Tv. thiocyanoxidans and Tv. thiocyanodenitrificans, albeit with low similarity to the reference sequence from Starkya novella (35\% identity in amino acid sequence). The alternative pathway uses adenylyl phosphosulfate (APS) as an intermediate and is catalyzed by adenylylsulfate reductase $(a p r \mathrm{AB})$ and sulfate adenylyltransferase (sat), both found in all three genomes. 


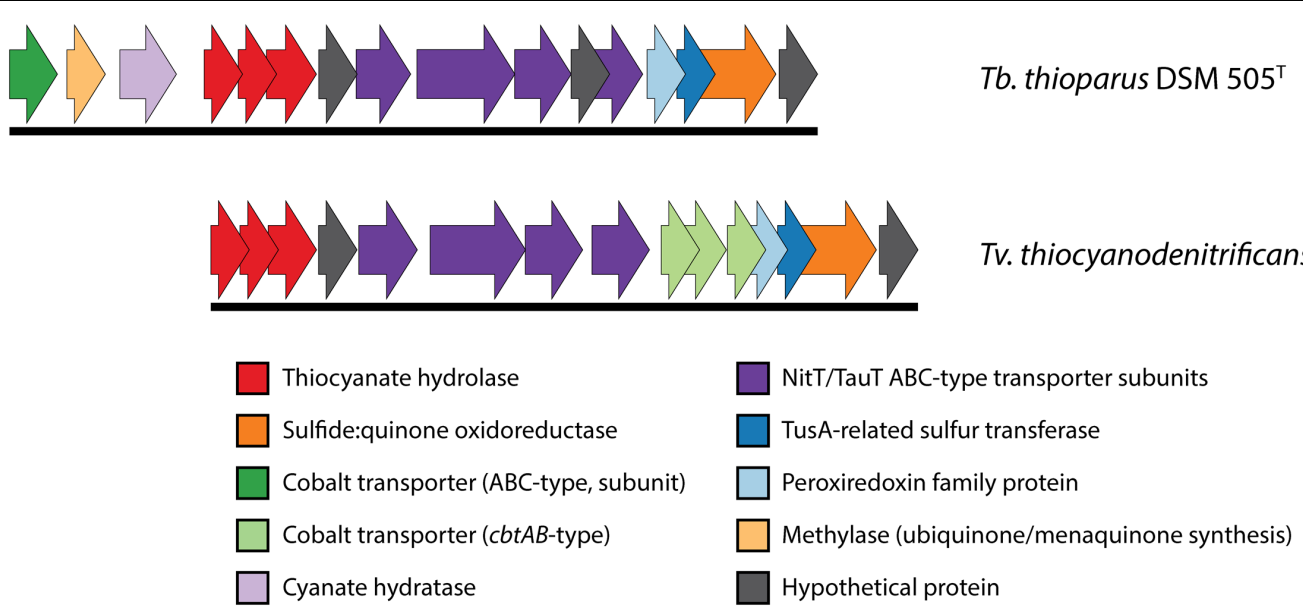

FIGURE 3 | Genomic context of thiocyanate hydrolase in Thiobacillus thioparus DSM 505 and Tv. thiocyanodenitrificans. The genomic layout is similar in both species. The main differences that were found here are the different cobalt uptake systems and the presence of a cyanase gene directly preceding the thiocyanate hydrolase genes in Tb. thioparus DSM 505. The IMG locus tags for the genes shown here are: Tb. thioparus, B058DRAFT_00790-00805; TV. thiocyanodenitrificans, ThithiDRAFT_0843-0857.

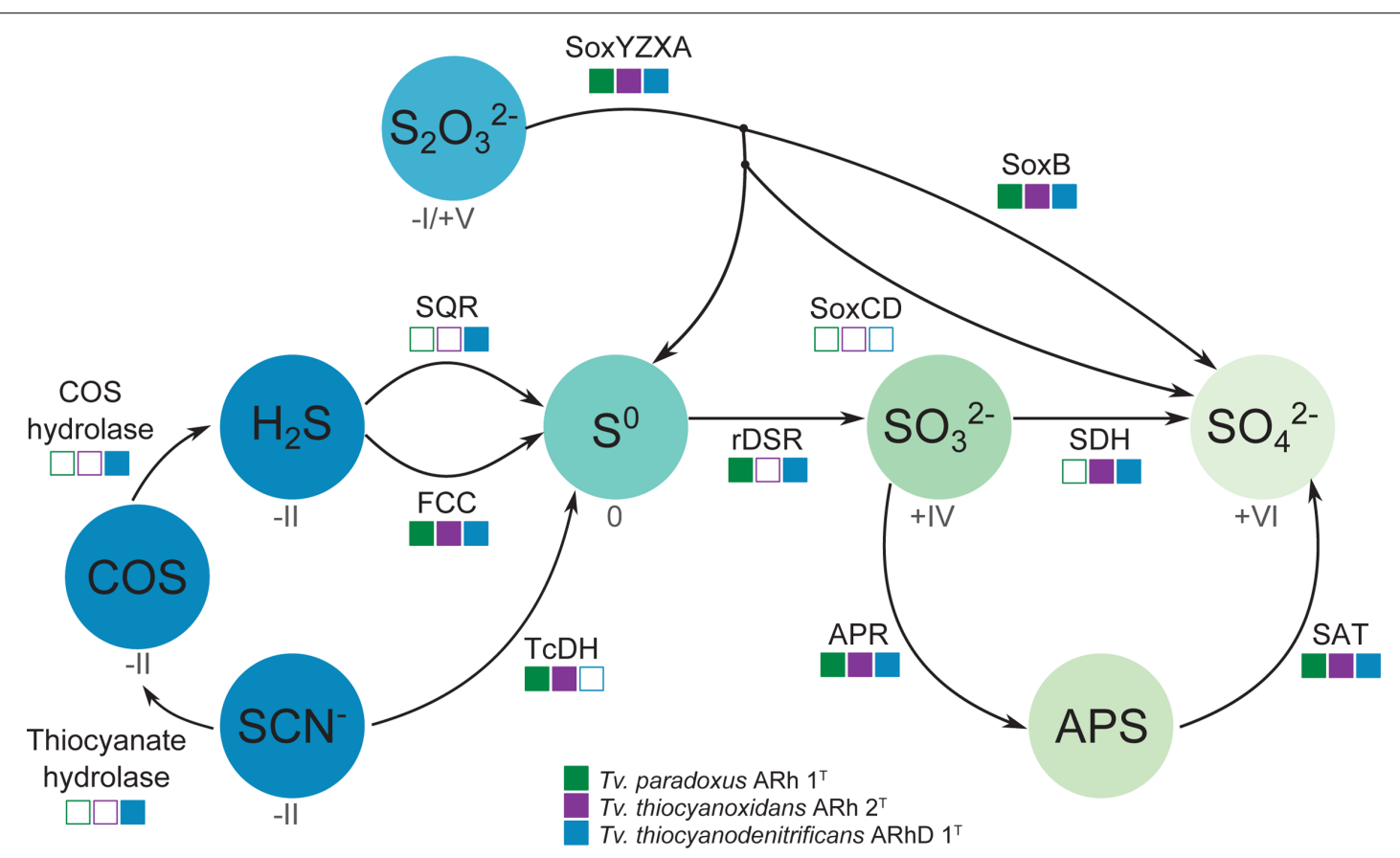

FIGURE 4 | Schematic overview of sulfur oxidation reactions in thiocyanate-oxidizing Thioalkalivibrio. Thiocyanate is either degraded to hydrogen sulfide via the carbonyl sulfide pathway (thiocyanate hydrolase to COS, then COS hydrolase to $\mathrm{H}_{2} \mathrm{~S}$ ), or oxidized to the level of elemental sulfur via the cyanate pathway (TcDH; TCDH). Sulfide can be oxidized to elemental sulfur by flavocytochrome c (FCC) or sulfide:quinone reductase (SQR). Thiosulfate is covalently bound to SoxYZ by SoxXA, after which SoxB cleaves the sulfane sulfur to form sulfate; the sulfane sulfur can be oxidized to sulfate by SoxCD or released as elemental sulfur. Zero-valent sulfur is oxidized to sulfite by the reverse dissimilatory sulfite reductase system (DSR) after which the sulfite is finally oxidized to sulfate directly (SDH) or indirectly (Adenylyl Phosposulfate Reductase - APR - to APS, then Sulfate Adenylyltransferase - SAT - to sulfate). The color gradient represents the oxidation state for each component (if known), from fully reduced (-II, blue) to fully oxidized (+IV, light green). The squares indicate the presence (solid) or absence (hollow) of each enzyme system in the three Thioalkalivibrio species studied here.

Of the three thiocyanate-oxidizing type strains, Tv. paradoxus and Tv. thiocyanodenitrificans possess a set of genes that provides a complete metabolic pathway for the oxidation of reduced sulfur compounds to sulfate. The enzyme complex responsible for the conversion of $\left[\mathrm{S}^{o}\right]$ to sulfite in Tv. thiocyanoxidans is presently unknown. It has been proposed that a system similar to cytoplasmic heterodisulfide reductase ( $h d r \mathrm{ABC})$, present in archaea and many anaerobic bacteria, functionally replaces $d s r$, 


\section{A}

\section{Allochromatium vinosum}

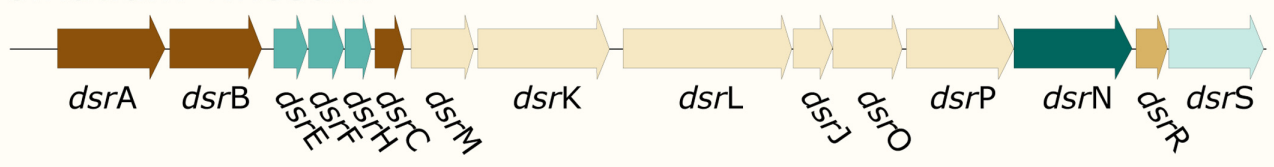

\section{Thioalkalivibrio paradoxus}

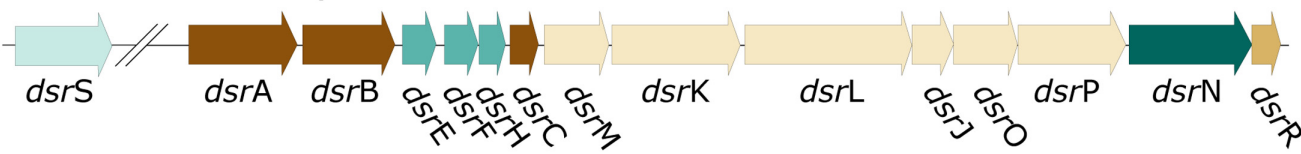

\section{Thioalkalivibrio thiocyanodenitrificans}

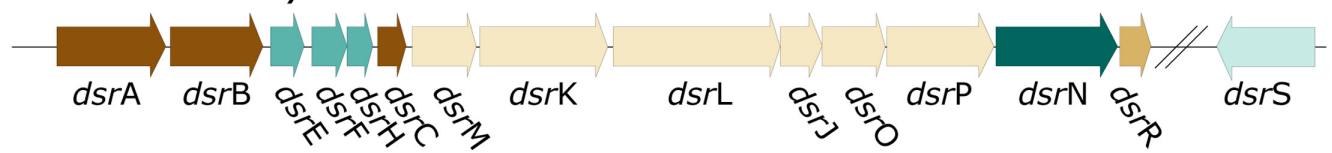

B

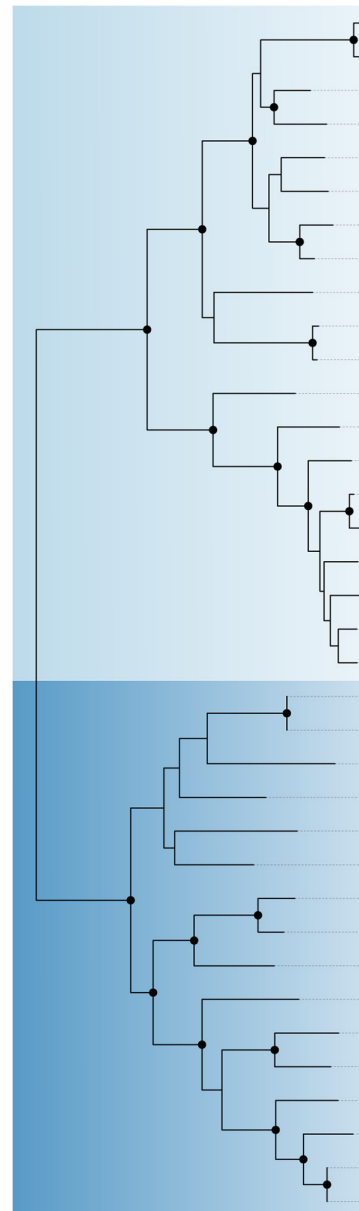

"Candidatus Ruthia magnifica str. Cm" (NC_008610)

"Candidatus Vesicomyosocius okutanii" (NC_009465) Alkalilimnicola ehrlichei MLHE1 (NC_008340) Halorhodospira halophila SL1 (NC_008789) BAC Clone MED13K09 (DQ068067) Allochromatium vinosum (U84760)

Thioalkalivibrio paradoxus (CP007029) Thioalkalivibrio thiocyanodenitrificans (NZ_KB900536) Thiobacillus denitrificans (NC_007404) Magnetospirillum magnetotacticum MS1 (NZ_AAAP01003703) Magnetospirillum magneticum AMB1 (AP007255) Magnetococcus marinus (NC_008576) Chlorobium phaeobacteroides BS1 (CP001101) Chlorobium limicola DSM 257 (CP001097) Chlorobium phaeovibrioides DSM 265 (CP000607) Chlorobium luteolum DSM 273 (NC_007512) Chlorobium clathratiforme BU1 (NZ_AAIK01000042)

- Chlorobium chlorochromatii CaD3 (NC_007514)

Prosthecochloris aestuarii DSM 271 (CP001108)

Chlorobium phaeobacteroides DSM 266 (CP000492) Desulfitobacterium hafniense DCB2 (NZ_AAAW04000003) Desulfitobacterium hafniense Y51 (NC_007907) Thermosinus carboxydivorans (NZ_AAWL01000006) Carboxydothermus hydrogenoformans Z2901 (NC_007503) Archaeoglobus fulgidus (NC_000917) Desulfotomaculum reducens MI1 (NC_000917) Wadden Sea sediment fosmid ws39f7 (CT025835) Wadden Sea sediment fosmid ws7f8 (CT025836) Hydrate Ridge sediment fosmid hr42c9 (СT025834) Syntrophobacter fumaroxidans MPOB (NC_008554) Deltaproteobacterium MLMS1 (NZ_AAQF01000532) Desulfotalea psychrophila (NC_006138) Desulfococcus oleovorans (NZ_AAWN01000034) Desulfovibrio desulfuricans (NC_007519) Desulfovibrio vulgaris DP4 (NC_008751) Desulfovibrio vulgaris str. Hildenborough (NC_002937)

Gammaproteobacteria

Unknown

Gammaproteobacteria

Betaproteobacteria

Alfaproteobacteria

Chlorobi

Euryarchaeota

Firmicutes

Unknown

Deltaproteobacteria of $T$. paradoxus and TV. thiocyanodenitrificans to that of the reference organism Allochromatium vinosum. (B) phylogenetic analysis of dsrAB sequences. The light blue clade comprises the dsrAB sequences from known sulfur-oxidizers, including TV. paradoxus and Tv. thiocyanodenitrificans. The dark blue clade contains sequences from known sulfate-reducing bacteria. Sequences from Pyrobaculum and Moorella were used as the outgroup, but pruned from the tree. 
and indeed $h d r$-like genes are found in many genomes that lack $d s r$ including the genome of $T v$. thiocyanoxidans, but evidence for its in vivo function is not available at present (Quatrini et al., 2009; Dahl, 2015).

\section{Carbon Metabolism}

It was previously shown, in a culture independent study of RuBisCO diversity in soda lakes, that Thioalkalivibrio contain RuBisCO of type Ia (Kovaleva et al., 2011). Many lithoautotrophic bacteria possess the capability to produce carboxysomes, specialized bacterial micro-compartments containing a high concentration of RuBisCO and carbonic anhydrase, the enzyme interconverting $\mathrm{CO}_{2}$ and $\mathrm{HCO}_{3}{ }^{-}$ (Heinhorst et al., 2014). Correspondingly, a search for these genes in Thioalkalivibrio was performed using sequences from the model gammaproteobacterial SOB Halothiobacillus neapolitanus (Cannon et al., 2003) as a reference; the results are shown in Figure 6. Both Tv. paradoxus and Tv. thiocyanoxidans possess RuBisCO small and large subunits ( $c b b \mathrm{~S}, c b b \mathrm{~L})$, and a complete cluster of alpha carboxysome genes: carbonic anhydrase csoS3 and carboxysome shell proteins $c s o \mathrm{~S} 2, \operatorname{cso} \mathrm{S} 4 \mathrm{~A} / \mathrm{B}$ and $c s o \mathrm{~S} 1 \mathrm{~A} / \mathrm{B} / \mathrm{C}$, with high similarity to those found in $H$. neapolitanus. $T v$. paradoxus has an additional beta-type carbonic anhydrase gene. The Tv. thiocyanodenitrificans genome contains only the genes for RuBisCO (two copies of each subunit) and two noncarboxysome-associated carbonic anhydrases, one beta- and one gamma-class. However, it lacks the genes that are involved in the formation of the carboxysomes, which is consistent with previous electron microscopy data indicating the absence of carboxysomes in this bacterium (Sorokin et al., 2013). This is an interesting observation, as it implies that Tv. thiocyanodenitrificans has a strong disadvantage in the competition for inorganic carbon. Previous studies in cyanobacteria have shown that the lack of a functional carboxysome leads to phenotypes that require significantly higher concentrations of $\mathrm{CO}_{2}$ (Price and Badger, 1989; Rae et al., 2013). Despite the fact that soda lakes have a large concentration of inorganic carbon (though, depending on the $\mathrm{pH}$, this may exist primarily as unavailable $\mathrm{CO}_{3}{ }^{2-}$ ), the fact that other Thioalkalivibrio do form carboxysomes (Sorokin et al., 2013) would suggest that Tv. thiocyanodenitrificans must have a strategy to prevent it from being out-competed. Its ability to grow anaerobically under denitrifying conditions, using thiosulfate or thiocyanate as electron donor might provide a niche where it can escape competition.

Specific transport enzymes for bicarbonate, such as SbtA and BicA known from alkalitolerant and haloalkaliphilic cyanobacteria (Sandrini et al., 2014; Kupriyanova and Samylina, 2015), were not detected in the investigated Thioalkalivibrio species. For SbtA it was previously shown that at least one other Thioalkalivibrio species, Tv. sulfidophilus, does not possess this gene, whereas Thioalkalivibrio sp. K90mix does (Muyzer et al., 2011a,b). A third bicarbonate uptake system from cyanobacteria, BCT1, is an ABC-type transporter. Although ABC-type transporters are detected in Thioalkalivibrio, it is not possible to infer their substrate from sequence information alone, which leaves bicarbonate transport in these organisms currently without a definitive explanation of the mechanism. A role for extracellular carbonic anhydrases in the $\mathrm{C}_{\mathrm{i}}$ acquisition at high $\mathrm{pH}$ was previously shown in the alkaliphilic cyanobacterium Microcoleus chthonoplastes (Kupriyanova et al., 2011). However, analysis of the amino acid sequences of the carbonic anhydrases present in the genomes of Tv. paradoxus and Tv. thiocyanodenitrificans using SignalP (Petersen et al., 2011) and TMHMM (Krogh et al., 2001) revealed no protein export signal peptides or transmembrane helices.

\section{Nitrogen Metabolism}

Complete denitrification is a multistep pathway from nitrate, via nitrite, nitric oxide and nitrous oxide, to molecular nitrogen $\left(\mathrm{N}_{2}\right)$ (Zumft, 1997). Tv. thiocyanodenitrificans is unique among the whole Thioalkalivibrio genus, being capable of complete denitrification (Sorokin et al., 2004). While some strains of Tv. thiocyanoxidans are capable of assimilatory nitrate reduction, neither Tv. thiocyanoxidans nor Tv. paradoxus is capable of using any of the $\mathrm{NO}_{\mathrm{x}}$ as electron acceptor (Sorokin et al., 2002). Nevertheless, in all three genomes an operon encoding the membrane-bound dissimilatory nitrate reductase (nar $\mathrm{GHI}$ ) is present (Table 3). In contrast, a putative cluster consisting of genes related to cytochrome $c d_{1}$-containing nitrite reductase (nirS), was only detected in Tv. thiocyanodenitrificans, in accordance with the spectroscopic evidence of nirS presence in this species that was previously published (Sorokin et al., 2004). Interestingly, a putative nitric oxide reductase cluster, consisting of nor CBQD was detected in both Tv. thiocyanodenitrificans and Tv. paradoxus (Table 3). The same holds true for nitrous oxide reductase (Table 3). In Tv. paradoxus this cluster has a different arrangement compared to that of $T v$. thiocyanodenitrificans, and it is located directly adjacent to the nitric oxide reductase cluster, rather than elsewhere in the genome. While the presence of a set of genes necessary for complete denitrification is consistent with the Tv. thiocyanodenitrificans phenotype, the nar, nor and nos gene clusters in Tv. paradoxus are apparently non-functional, since this organism is incapable of using $\mathrm{NO}_{\mathrm{x}}$, both in assimilatory and dissimilatory modes (Sorokin et al., 2002).

Since Tv. paradoxus is most closely related to $T v$. nitratireducens (Sorokin et al., 2013), a member of a denitrifying consortium, which grows anaerobically by nitrate reduction to nitrite, but is incapable of further denitrification (Sorokin et al., 2003), it might be speculated that, perhaps, both species descended from a complete denitrifying ancestor but then evolved in different habitats.

\section{Adaptations to Haloalkaline Environments}

Most salt-tolerant bacteria are capable of synthesizing organic compatible solutes to resist the osmotic pressure from the hypersaline environment. Previous studies on an extremely salt-tolerant Thioalkalivibrio sp. ALJ15, have shown that glycine betaine is the dominant solute produced, with sucrose as a minor fraction (Banciu et al., 2005). In all three thiocyanate-utilizing species, the BCCT type betaine transporter bet $\mathrm{L}$ (Ziegler et al., 2010) was 


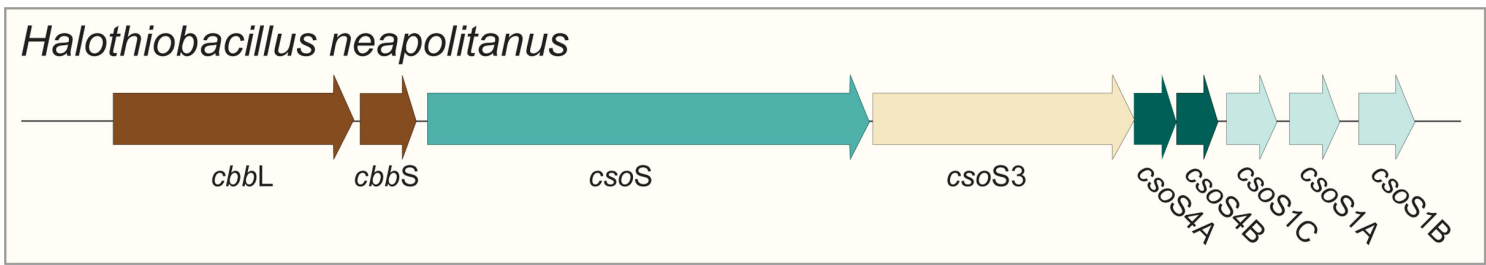

Thioalkalivibrio paradoxus ARh $1^{\top}$

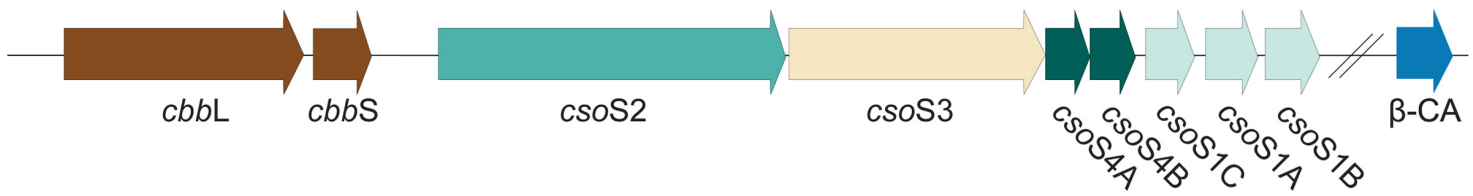

Thioalkalivibrio thiocyanoxidans ARh $2^{\top}$

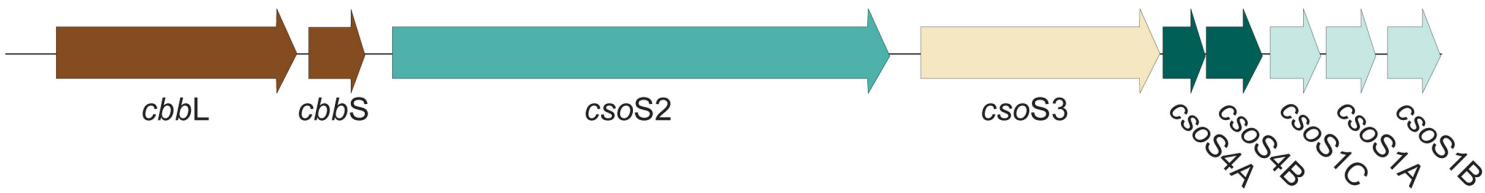

Thioalkalivibrio thiocyanodenitrificans $\mathrm{ARhD} 1^{\top}$

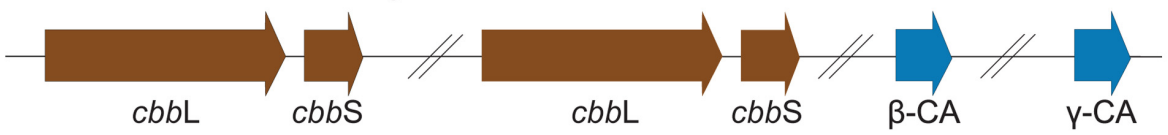

FIGURE 6 | RuBisCO and carboxysome genes detected in the Thioalkalivibrio genomes. The genes for RuBisCO and carboxysome formation were compared to the genes from the model organism Halothiobacillus neapolitanus. CbbL/S: respectively large and small subunits of RuBisCO; CsoS1A/B/C: major carboxysome shell proteins (due to high similarity these cannot be distinguished by BLAST, therefore the order in which they appear in $H$. neapolitanus is assumed); CsoS2: structural protein; CsoS3: carboxysome shell carbonic anhydrase; CsoS4A/B: structural proteins; CA: carbonic anhydrase not associated with carboxysomes. The IMG locus tags for the genes shown here are: TV. paradoxus, Thith_2516-2524 (carboxysome cluster) and Thith_2150 (carbonic anhydrase); TV. thiocyanoxidans, G372DRAFT_00040-0048; Tv. thiocyanodenitrificans, ThithiDRAFT_0610-0611 (cbbLS 1), ThithiDRAFT_2059-2060 (cbbLS 2), ThithiDRAFT_0715 ( $\beta$-type carbonic anhydrase) and ThithiDRAFT_2393 ( $\gamma$-type carbonic anhydrase).

TABLE 3 | Presence of genes for denitrification in Thioalkalivibrio.

\begin{tabular}{|c|c|c|c|c|}
\hline Species & Nitrate reductase (nar) & Nitrite reductase (nir) & Nitric oxide reductase (nor) & Nitrous oxide reductase (nos) \\
\hline TV. paradoxus ARh $1^{\top}$ & Yes & Partial & Yes & Yes \\
\hline TV. thiocyanodenitrificans ARhD $1^{\top}$ & Yes* & Yes & Yes & Yes \\
\hline Tv. thiocyanoxidans ARh $2^{\top}$ & Partial & Not found & Not found & Not found \\
\hline
\end{tabular}

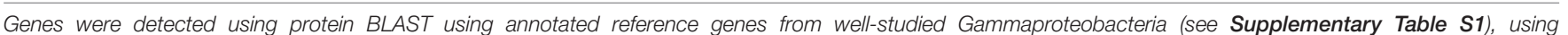

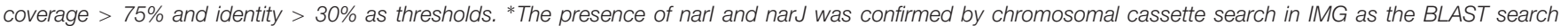
with Escherichia coli reference sequences did not find these genes.

detected, as well as genes for the synthesis of glycine betaine via sarcosine (glycine/sarcosine N-methyltransferase and sarcosine/dimethylglycine N-methyltransferase) (Nyyssölä et al., 2000). The key enzyme for glycine betaine production from choline, choline dehydrogenase, was not found in these species. Likewise, sucrose phosphate synthase was found in all three species. Key genes for ectoine biosynthesis, ectABC, were not detected. These results are compatible with previous studies on the genomes of other Thioalkalivibrio type strains (Muyzer et al., 2011a,b).

In addition to the osmotic pressure, soda lakes are energetically challenging by imposition of an unfavorable $\mathrm{pH}$ gradient across the cell membrane. Possible adaptations to this include the use of sodium energetics rather than proton energetics, secondary sodium pumps, such as sodium-dependent sym- and antiporters, and structural adaptations, such as the incorporation of squalene and cardiolipin in the cell membrane to decrease the rate of proton leakage (Banciu and Muntyan, 2015). Genes for the primary sodium-pumping NADH:quinone oxidoreductase $\mathrm{Na}^{+}-\mathrm{NQR}$, extensively studied in alkalitolerant Vibrio species (Barquera, 2014), were not detected in any of the three genomes. Instead, a complete cluster of genes for the ferredoxin:NAD ${ }^{+}$oxidoreductase Rnf ( $r n f$ ABCDGE), of which a sodium-translocating variant was first described in Acetobacterium woodii (Biegel et al., 2011), was found in Tv. paradoxus and Tv. thiocyanodenitrificans. Tv. thiocyanoxidans 
was shown to only have $r n f \mathrm{ABCE}$, lacking $r n f \mathrm{DG}$. Unfortunately, to date, no data on conserved amino acid residues involved in sodium coordination has been published. This makes it impossible to infer the type of $r n f\left(\mathrm{Na}^{+}\right.$or $\mathrm{H}^{+}$translocating) from the sequence alone. Recently, a first example of a sodiumpumping cytochrome $c$ oxidase, type $c b b_{3}$, from $T v$. versutus AL $2^{\mathrm{T}}$ was discovered (Muntyan et al., 2015). Detailed analysis of the protein sequence in that study revealed a number of amino acid residues that are essential to the sodium-pumping function of this enzyme. In the same study, it was shown that Tv. paradoxus ARh $1^{\mathrm{T}}$ also possesses the $\mathrm{Na}^{+}$-pumping cytochrome $c b b_{3}$, based on sequence information. A BLAST search of the three genomes in this study reveals that all three possess the $\mathrm{Na}^{+}$-translocating $c b b_{3}$ cytochrome oxidase and that both $T v$. paradoxus and Tv. thiocyanodenitrificans have an additional $\mathrm{H}^{+}$-translocating copy of this gene (Supplementary Figure S1). It was previously shown that Thioalkalivibrio do not possess sodium-driven ATP synthase genes (Hicks et al., 2010). A primary sodium cycle is still possible, with cytochrome $c b b_{3}$ oxidase exporting sodium ions and a sodium driven $r n f$ complex using the sodium motive force to drive the reverse electron flow for the NADH synthesis common in chemolithoautotrophic bacteria. However, at present, there is no experimental evidence for such a system.

Squalene, a neutral lipid, is an isoprenoid hydrocarbon that is a component in the cell membrane of some of the alkaliphilic bacteria in which it reduces proton leakage (Hauß et al., 2002). Tv. paradoxus, Tv. thiocyanodenitrificans, and Tv. thiocyanoxidans all possess a full set of genes ( $d x s, d x r$, ispACDEFGH) for producing squalene from glyceraldehyde3-phosphate and pyruvate via the non-mevalonate pathway (Eisenreich et al., 2004). According to the total lipid analysis of Tv. paradoxus, lanosterol (a product of linear squalene cyclization) comprised approximately $50 \%$ of the total membrane lipids (our unpublished data). Cardiolipin is a negatively charged polar membrane phospholipid that can act as a proton trap, stabilizes respiratory complexes and is involved in the saltstress response (Haines and Dencher, 2002; De Leo et al., 2009; Arias-Cartin et al., 2012), although recent research has shown that it is not absolutely required for oxidative phosphorylation in alkaliphilic Bacillus pseudofirmus (Liu et al., 2014). In bacteria it is synthesized from two phosphatidylglycerol molecules by cardiolipin synthase, an enzyme with two phospholipase D domains (Tian et al., 2012). Again, in all three species genes aligning to Escherichia coli cardiolipin synthase were found, containing two phospholipase D domains, albeit with low sequence similarity (25-38\%). However, only Tv. thiocyanoxidans possesses three genes that distinctly align to the three subunits of cardiolipin synthase. In the other two species, only two genes were found.

\section{REFERENCES}

Altschul, S. F., Gish, W., Miller, W., Myers, E. W., and Lipman, D. J. (1990). Basic local alignment search tool. J. Mol. Biol. 215, 403-410. doi: 10.1016/S00222836(05)80360-2

\section{CONCLUSION}

In this paper we describe the first comparative genomics study of three thiocyanate-oxidizing Thioalkalivibrio isolated from soda lakes. We show the presence of the recently described thiocyanate dehydrogenase in Tv. thiocyanoxidans and Tv. paradoxus, as well as in eight additional Thioalkalivibrio genomes. Analysis of the genomic context of this gene reveals the presence of genes for the uptake of a copper co-factor (copCD) and for the transport of the enzyme to the periplasm (tat A), sulfide dehydrogenase $(f c c \mathrm{AB})$ and a number of genes of unknown function. There are two genotypes of this cluster, whose distribution correlates with Thioalkalivibrio phylogenetic relatedness. Two genes are absent from this cluster in Thioalkalivibrio sp. AKL 11 and appear to decrease its ability to adapt to growth on thiocyanate, suggesting that this information could be used in for example strain selection for biotechnology applications. Tv. thiocyanodenitrificans utilizes the COS pathway and its genome correspondingly contains genes for thiocyanate hydrolase. Tv. thiocyanoxidans stands out from the other two for its lack of the rDSR pathway and the presence of a putative sulfite dehydrogenase. All three species fix carbon using type Ia RuBisCO and Tv, thiocyanoxidans and Tv. paradoxus additionally have genes for a carbonconcentrating mechanism. The absence of these genes in $T v$. thiocyanodenitrificans suggests it uses a different competitive strategy.

\section{AUTHOR CONTRIBUTIONS}

TB performed the various analyses and drafted the manuscript, LO and GM assisted in the interpretation of results and, together with DS, provided critical review of the manuscript. All authors have read and approved the final version of the manuscript.

\section{FUNDING}

TB, LO, and GM are supported by the ERC Advanced Grant PARASOL (No. 322551). DS is supported by RBFR Grant 16-0400035.

\section{SUPPLEMENTARY MATERIAL}

The Supplementary Material for this article can be found online at: http://journal.frontiersin.org/article/10.3389/fmicb. 2017.00254/full\#supplementary-material

TABLE S1 | The list of reference sequences used for detecting genes in the three Thioalkalivibrio genomes and the associated BLAST results.

Arias-Cartin, R., Grimaldi, S., Arnoux, P., Guigliarelli, B., and Magalon, A. (2012). Cardiolipin binding in bacterial respiratory complexes: structural and functional implications. Biochim. Biophys. Acta 1817, 1937-1949. doi: 10.1016/j.bbabio.2012. 04.005 
Banciu, H., Sorokin, D. Y., Rijpstra, W. I. C., Sinninghe Damsté, J. S., Galinski, E. A., Takaichi, S., et al. (2005). Fatty acid, compatible solute and pigment composition of obligately chemolithoautotrophic alkaliphilic sulfur-oxidizing bacteria from soda lakes. FEMS Microbiol. Lett. 243, 181-187. doi: 10.1016/j. femsle.2004.12.004

Banciu, H. L., and Muntyan, M. S. (2015). Adaptive strategies in the doubleextremophilic prokaryotes inhabiting soda lakes. Curr. Opin. Microbiol. 25, 73-79. doi: 10.1016/j.mib.2015.05.003

Barquera, B. (2014). The sodium pumping NADH:quinone oxidoreductase $\left(\mathrm{Na}^{+}\right.$NQR), a unique redox-driven ion pump. J. Bioenerg. Biomembr. 46, 289-298. doi: 10.1007/s10863-014-9565-9

Berben, T., Sorokin, D. Y., Ivanova, N., Pati, A., Kyrpides, N., Goodwin, L. A., et al. (2015a). Complete genome sequence of Thioalkalivibrio paradoxus type strain ARh $1^{\mathrm{T}}$, an obligately chemolithoautotrophic haloalkaliphilic sulfur-oxidizing bacterium isolated from a Kenyan soda lake. Stand. Genomic Sci. 10:105. doi: 10.1186/s40793-015-0097-7

Berben, T., Sorokin, D. Y., Ivanova, N., Pati, A., Kyrpides, N., Goodwin, L. A., et al. (2015b). Partial genome sequence of the haloalkaliphilic soda lake bacterium Thioalkalivibrio thiocyanoxidans ARh $2^{\mathrm{T}}$. Stand. Genomic Sci. 10:85. doi: 10. 1186/s40793-015-0078-x

Berben, T., Sorokin, D. Y., Ivanova, N., Pati, A., Kyrpides, N., Goodwin, L. A., et al. (2015c). Partial genome sequence of Thioalkalivibrio thiocyanodenitrificans ARhD $1^{\mathrm{T}}$, a chemolithoautotrophic haloalkaliphilic sulfur-oxidizing bacterium capable of complete denitrification. Stand. Genomic Sci. 10:84. doi: 10.1186/ s40793-015-0080-3

Betts, P. M., Rinder, D. F., and Fleeker, J. R. (1979). Thiocyanate utilization by an Arthrobacter. Can. J. Microbiol. 25, 1277-1282. doi: 10.1139/m79-201

Bezsudnova, E. Y., Sorokin, D. Y., Tikhonova, T. V., and Popov, V. O. (2007). Thiocyanate hydrolase, the primary enzyme initiating thiocyanate degradation in the novel obligately chemolithoautotrophic halophilic sulfur-oxidizing bacterium Thiohalophilus thiocyanoxidans. Biochim. Biophys. Acta 1774, 15631570. doi: 10.1016/j.bbapap.2007.09.003

Bhunia, F., Saha, N. C., and Kaviraj, A. (2000). Toxicity of thiocyanate to fish, plankton, worm, and aquatic ecosystem. Bull. Environ. Contam. Toxicol. 64, 197-204. doi: 10.1007/s001289910030

Biegel, E., Schmidt, S., González, J. M., and Müller, V. (2011). Biochemistry, evolution and physiological function of the Rnf complex, a novel ion-motive electron transport complex in prokaryotes. Cell. Mol. Life Sci. 68, 613-634. doi: 10.1007/s00018-010-0555-8

Brauer, V. F. H., Below, H., Kramer, A., Führer, D., and Paschke, R. (2006). The role of thiocyanate in the etiology of goiter in an industrial metropolitan area. Eur. J. Endocrinol. 154, 229-235. doi: 10.1530/eje.1.02076

Cannon, G. C., Baker, S. H., Soyer, F., Johnson, D. R., Bradburne, C. E., Mehlman, J. L., et al. (2003). Organization of carboxysome genes in the thiobacilli. Curr. Microbiol. 46, 115-119. doi: 10.1007/s00284-0023825-3

Cipollone, R., Ascenzi, P., and Visca, P. (2007). Common themes and variations in the rhodanese superfamily. IUBMB Life 59, 51-59. doi: 10.1080/ 15216540701206859

Cock, P. J. A., Antao, T., Chang, J. T., Chapman, B. A., Cox, C. J., Dalke, A., et al. (2009). Biopython: freely available Python tools for computational molecular biology and bioinformatics. Bioinformatics 25, 1422-1423. doi: 10 . 1093/bioinformatics/btp163

Dahl, C. (2015). Cytoplasmic sulfur trafficking in sulfur-oxidizing prokaryotes. IUBMB Life 67, 268-274. doi: 10.1002/iub.1371

De Leo, V., Catucci, L., Ventrella, A., Milano, F., Agostiano, A., and Corcelli, A. (2009). Cardiolipin increases in chromatophores isolated from Rhodobacter sphaeroides after osmotic stress: structural and functional roles. J. Lipid Res. 50, 256-264. doi: 10.1194/jlr.M800312-JLR200

du Plessis, C. A., Barnard, P., Muhlbauer, R. M., and Naldrett, K. (2001). Empirical model for the autotrophic biodegradation of thiocyanate in an activated sludge reactor. Lett. Appl. Microbiol. 32, 103-107. doi: 10.1046/j.1472-765x.2001. 00859. $\mathrm{x}$

Eisenreich, W., Bacher, A., Arigoni, D., and Rohdich, F. (2004). Biosynthesis of isoprenoids via the non-mevalonate pathway. Cell. Mol. Life Sci. 61, 1401-1426. doi: 10.1007/s00018-004-3381-z

Ghosh, W., and Dam, B. (2009). Biochemistry and molecular biology of lithotrophic sulfur oxidation by taxonomically and ecologically diverse bacteria and archaea. FEMS Microbiol. Rev. 33, 999-1043. doi: 10.1111/j.1574-6976. 2009.00187.x

Gould, W. D., King, M., Mohapatra, B. R., Cameron, R. A., Kapoor, A., and Koren, D. W. (2012). A critical review on destruction of thiocyanate in mining effluents. Miner. Eng. 34, 38-47. doi: 10.1016/j.mineng.2012.04.009

Grant, W. D., and Sorokin, D. Y. (2011). "Distribution and diversity of soda lake alkaliphiles," in Extremophiles Handbook, ed. K. Horikoshi (Tokyo: Springer Japan), 27-54. doi: 10.1007/978-4-431-53898-1_3

Haines, T. H., and Dencher, N. A. (2002). Cardiolipin: a proton trap for oxidative phosphorylation. FEBS Lett. 528, 35-39. doi: 10.1016/S0014-5793(02)03292-1

Hauß, T., Dante, S., Dencher, N. A., and Haines, T. H. (2002). Squalane is in the midplane of the lipid bilayer: implications for its function as a proton permeability barrier. Biochim. Biophys. Acta 1556, 149-154. doi: 10.1016/ S0005-2728(02)00346-8

Heinhorst, S., Cannon, G. C., and Shively, J. M. (2014). "Nanomicrobiology," in Carboxysomes and Their Structural Organization in Prokaryotes, eds L. L. Barton, D. A. Bazylinski, and H. Xu (New York, NY: Springer).

Hicks, D. B., Liu, J., Fujisawa, M., and Krulwich, T. A. (2010). $\mathrm{F}_{1} \mathrm{~F}_{0}$-ATP synthases of alkaliphilic bacteria: lessons from their adaptations. Biochim. Biophys. Acta 1797, 1362-1377. doi: 10.1016/j.bbabio.2010.02.028

Huddy, R. J., Van Zyl, A. W., Van Hille, R. P., and Harrison, S. T. L. (2015). Characterisation of the complex microbial community associated with the ASTER $^{\text {TM }}$ thiocyanate biodegradation system. Miner. Eng. 76, 65-71. doi: 10. 1016/j.mineng.2014.12.011

Kantor, R. S., van Zyl, A. W., van Hille, R. P., Thomas, B. C., Harrison, S. T. L., and Banfield, J. F. (2015). Bioreactor microbial ecosystems for thiocyanate and cyanide degradation unravelled with genome-resolved metagenomics. Environ. Microbiol. 17, 4929-4941. doi: 10.1111/1462-2920.12936

Kappler, U., and Dahl, C. (2001). Enzymology and molecular biology of prokaryotic sulfite oxidation. FEMS Microbiol. Lett. 203, 1-9. doi: 10.1111/j.1574-6968.2001. tb10813.x

Katayama, Y., Hiraishit, A., Kuraishi, H., Hiraishi, A., and Kuraishi, H. (1995). Paracoccus thiocyanatus sp. nov., a new species of thiocyanate-utilizing facultative chemolithotroph, and transfer of Thiobacillus versutus to the genus Paracoccus as Paracoccus versutus comb. nov. with emendation of the genus. Microbiology 141, 1469-1477. doi: 10.1099/13500872-141-6-1469

Katayama, Y., Matsushita, Y., Kaneko, M., Kondo, M., Mizuno, T., and Nyunoya, H. (1998). Cloning of genes coding for the three subunits of thiocyanate hydrolase of Thiobacillus thioparus THI 115 and their evolutionary relationships to nitrile hydratase. J. Bacteriol. 180, 2583-2589.

Kelly, D. P., and Wood, A. P. (2000). Confirmation of Thiobacillus denitrificans as a species of the genus Thiobacillus, in the beta-subclass of the Proteobacteria, with strain NCIMB 9548 as the type strain. Int. J. Syst. Bacteriol. 50, 547-550. doi: 10.1099/00207713-50-2-547

Kovaleva, O. L., Tourova, T. P., Muyzer, G., Kolganova, T. V., and Sorokin, D. Y. (2011). Diversity of RuBisCO and ATP citrate lyase genes in soda lake sediments. FEMS Microbiol. Ecol. 75, 37-47. doi: 10.1111/j.1574-6941.2010. 00996.x

Krogh, A., Larsson, B., von Heijne, G., and Sonnhammer, E. L. (2001). Predicting transmembrane protein topology with a hidden markov model: application to complete genomes. J. Mol. Biol. 305, 567-580. doi: 10.1006/jmbi.2000. 4315

Krzywinski, M., Schein, J., Birol, I., Connors, J., Gascoyne, R., Horsman, D., et al. (2009). Circos: an information aesthetic for comparative genomics. Genome Res. 19, 1639-1645. doi: 10.1101/gr.092759.109

Kupriyanova, E. V., and Samylina, O. S. (2015). $\mathrm{CO}_{2}$-concentrating mechanism and its traits in haloalkaliphilic cyanobacteria. Microbiology 84, 112-124. doi: $10.1134 /$ S0026261715010075

Kupriyanova, E. V., Sinetova, M. A., Cho, S. M., Park, Y.-I., Los, D. A., and Pronina, N. A. (2011). Extracellular $\beta$-class carbonic anhydrase of the alkaliphilic cyanobacterium Microcoleus chthonoplastes. J. Photochem. Photobiol. B Biol. 103, 78-86. doi: 10.1016/j.jphotobiol.2011.01.021

Langille, M. G. I., and Brinkman, F. S. L. (2009). IslandViewer: an integrated interface for computational identification and visualization of genomic islands. Bioinformatics 25, 664-665. doi: 10.1093/bioinformatics/btp030

Langmead, B., and Salzberg, S. L. (2012). Fast gapped-read alignment with Bowtie 2. Nat. Methods 9, 357-359. doi: 10.1038/nmeth.1923 
Lee, C., Kim, J., Chang, J., and Hwang, S. (2003). Isolation and identification of thiocyanate utilizing chemolithotrophs from gold mine soils. Biodegradation 14, 183-188. doi: 10.1023/A:1024256932414

Lee, J., and Kwon, H. (2015). In vitro metabolic conversion of the organic breakdown products of glucosinolate to goitrogenic thiocyanate anion. J. Sci. Food Agric. 95, 2244-2251. doi: 10.1002/jsfa.6943

Li, H., Handsaker, B., Wysoker, A., Fennell, T., Ruan, J., Homer, N., et al. (2009). The sequence alignment/map format and SAMtools. Bioinformatics 25, 20782079. doi: 10.1093/bioinformatics/btp352

Liu, J., Ryabichko, S., Bogdanov, M., Fackelmayer, O. J., Dowhan, W., and Krulwich, T. A. (2014). Cardiolipin is dispensable for oxidative phosphorylation and non-fermentative growth of alkaliphilic Bacillus pseudofirmus OF4. J. Biol. Chem. 289, 2960-2971. doi: 10.1074/jbc.M113.536193

Loy, A., Duller, S., Baranyi, C., Mußmann, M., Ott, J., Sharon, I., et al. (2009). Reverse dissimilatory sulfite reductase as phylogenetic marker for a subgroup of sulfur-oxidizing prokaryotes. Environ. Microbiol. 11, 289-299. doi: 10.1111/ j.1462-2920.2008.01760.x

Markowitz, V. M., Chen, I.-M. A., Palaniappan, K., Chu, K., Szeto, E., Pillay, M., et al. (2014). IMG 4 version of the integrated microbial genomes comparative analysis system. Nucleic Acids Res. 42, D560-D567. doi: 10.1093/nar/gkt963

McDermott, P. F., McMurry, L. M., Podglajen, I., Dzink-Fox, J. L., Schneiders, T., Draper, M. P., et al. (2008). The marC Gene of Escherichia coli is not involved in multiple antibiotic resistance. Antimicrob. Agents Chemother. 52, 382-383. doi: 10.1128/AAC.00930-07

Mu, T., Zhou, J., Yang, M., and Xing, J. (2016). Complete genome sequence of Thialkalivibrio versutus D301 isolated from Soda Lake in northern China, a typical strain with great ability to oxidize sulfide. J. Biotechnol. 227, 21-22. doi: 10.1016/j.jbiotec.2016.04.019

Muntyan, M. S., Cherepanov, D. A., Malinen, A. M., Bloch, D. A., Sorokin, D. Y., Severina, I. I., et al. (2015). Cytochrome $c b b_{3}$ of Thioalkalivibrio is a $\mathrm{Na}^{+}$pumping cytochrome oxidase. Proc. Natl. Acad. Sci. U.S.A. 112, 7695-7700. doi: $10.1073 /$ pnas. 1417071112

Muyzer, G., Sorokin, D. Y., Mavromatis, K., Lapidus, A., Clum, A., Ivanova, N., et al. (2011a). Complete genome sequence of "Thioalkalivibrio sulfidophilus" HL-EbGr7. Stand. Genomic Sci. 4, 23-35. doi: 10.4056/sigs.1483693

Muyzer, G., Sorokin, D. Y., Mavromatis, K., Lapidus, A., Foster, B., Sun, H., et al. (2011b). Complete genome sequence of Thioalkalivibrio sp. K90mix. Stand. Genomic Sci. 5, 341-355. doi: 10.4056/sigs.2315092

Nyyssölä, A., Kerovuo, J., Kaukinen, P., von Weymarn, N., and Reinikainen, T. (2000). Extreme halophiles synthesize betaine from glycine by methylation. J. Biol. Chem. 275, 22196-22201. doi: 10.1074/jbc.M910111199

Parks, D. H., Imelfort, M., Skennerton, C. T., Hugenholtz, P., and Tyson, G. W. (2014). CheckM: assessing the quality of microbial genomes recovered from isolates, single cells, and metagenomes. PeerJ Prepr. 2. doi: 10.1101/gr. 186072.114

Petersen, T. N., Brunak, S., von Heijne, G., and Nielsen, H. (2011). SignalP 4.0: discriminating signal peptides from transmembrane regions. Nat. Methods 8, 785-786. doi: 10.1038/nmeth.1701

Price, G. D., and Badger, M. R. (1989). Expression of human carbonic anhydrase in the cyanobacterium Synechococcus PCC7942 creates a high $\mathrm{CO}_{2}$-requiring phenotype: evidence for a central role for carboxysomes in the $\mathrm{CO}_{2}$ concentrating mechanism. Plant Physiol. 91, 505-513. doi: 10.1104/pp.91. 2.505

Quatrini, R., Appia-Ayme, C., Denis, Y., Jedlicki, E., Holmes, D. S., and Bonnefoy, V. (2009). Extending the models for iron and sulfur oxidation in the extreme acidophile Acidithiobacillus ferrooxidans. BMC Genomics 10:394. doi: 10.1186/1471-2164-10-394

Rae, B. D., Long, B. M., Badger, M. R., and Price, G. D. (2013). Functions, compositions, and evolution of the two types of carboxysomes: polyhedral microcompartments that facilitate $\mathrm{CO}_{2}$ fixation in cyanobacteria and some proteobacteria. Microbiol. Mol. Biol. Rev. 77, 357-379. doi: 10.1128/MMBR. 00061-12

Ryu, B. G., Kim, J., Farooq, W., Han, J. I., Yang, J. W., and Kim, W. (2014). Algal-bacterial process for the simultaneous detoxification of thiocyanate-containing wastewater and maximized lipid production under photoautotrophic/photoheterotrophic conditions. Bioresour. Technol. 162, 70-79. doi: 10.1016/j.biortech.2014.03.084
Sandrini, G., Matthijs, H. C. P., Verspagen, J. M. H., Muyzer, G., and Huisman, J. (2014). Genetic diversity of inorganic carbon uptake systems causes variation in $\mathrm{CO}_{2}$ response of the cyanobacterium Microcystis. ISME J. 8, 589-600. doi: 10.1038/ismej.2013.179

Sievers, F., Wilm, A., Dineen, D., Gibson, T. J., Karplus, K., Li, W., et al. (2011). Fast, scalable generation of high-quality protein multiple sequence alignments using Clustal Omega. Mol. Syst. Biol. 7:539. doi: 10.1038/msb. 2011.75

Soderlund, C., Nelson, W., Shoemaker, A., and Paterson, A. (2006). SyMAP: a system for discovering and viewing syntenic regions of FPC maps. Genome Res. 16, 1159-1168. doi: 10.1101/gr.5396706

Sorokin, D. Y., Abbas, B., Van Zessen, E., and Muyzer, G. (2014a). Isolation and characterization of an obligately chemolithoautotrophic Halothiobacillus strain capable of growth on thiocyanate as an energy source. FEMS Microbiol. Lett. 354, 69-74. doi: 10.1111/1574-6968.12432

Sorokin, D. Y., Banciu, H., Robertson, L. A., Kuenen, J. G., Muntyan, M. S., and Muyzer, G. (2013). "Halophilic and haloalkaliphilic sulfur-oxidizing bacteria," in The Prokaryotes: Prokaryotic Physiology and Biochemistry, eds E. Rosenberg, E. F. DeLong, S. Lory, E. Stackebrandt, and F. Thompson (Heidelberg: Springer), 529-554. doi: 10.1007/978-3-642-30141-4_77

Sorokin, D. Y., Berben, T., Melton, E. D., Overmars, L., Vavourakis, C. D., and Muyzer, G. (2014b). Microbial diversity and biogeochemical cycling in soda lakes. Extremophiles 18, 791-809. doi: 10.1007/s00792-014-0670-9

Sorokin, D. Y., Kovaleva, O. L., Tourova, T. P., and Muyzer, G. (2010). Thiohalobacter thiocyanaticus gen. nov., sp. nov., a moderately halophilic, sulfur-oxidizing gammaproteobacterium from hypersaline lakes, that utilizes thiocyanate. Int. J. Syst. Evol. Microbiol. 60, 444-450. doi: 10.1099/ijs. 0.012880-0

Sorokin, D. Y., Lysenko, A. M., Mityushina, L. L., Tourova, T. P., Jones, B. E., Rainey, F. A., et al. (2001a). Thioalkalimicrobium aerophilum gen. nov., sp. nov. and Thioalkalimicrobium sibericum sp. nov., and Thioalkalivibrio versutus gen. nov., sp. nov., Thioalkalivibrio nitratis sp. nov. and Thioalkalivibrio denitrificans sp. nov., novel obligately alkaliphilic and obligately chemolithoautotropic sulfur-oxidizing bacteria from soda lakes. Int. J. Syst. Evol. Microbiol. 51, $565-580$.

Sorokin, D. Y., Tourova, T. P., Antipov, A. N., Muyzer, G., and Kuenen, J. G. (2004). Anaerobic growth of the haloalkaliphilic denitrifying sulfur-oxidizing bacterium Thialkalivibrio thiocyanodenitrificans sp. nov. with thiocyanate. Microbiology 150, 2435-2442. doi: 10.1099/mic.0.27015-0

Sorokin, D. Y., Tourova, T. P., Bezsudnova, E. Y., Pol, A., and Muyzer, G. (2007). Denitrification in a binary culture and thiocyanate metabolism in Thiohalophilus thiocyanoxidans gen. nov. sp. nov. - A moderately halophilic chemolithoautotrophic sulfur-oxidizing Gammaproteobacterium from hypersaline lakes. Arch. Microbiol. 187, 441-450. doi: 10.1007/s00203006-0208-3

Sorokin, D. Y., Tourova, T. P., Lysenko, A. M., and Kuenen, J. G. (2001b). Microbial thiocyanate utilization under highly alkaline conditions. Appl. Environ. Microbiol. 67, 528-538. doi: 10.1128/AEM.67.2.528-538.2001

Sorokin, D. Y., Tourova, T. P., Lysenko, A. M., Mityushina, L. L., and Kuenen, J. G. (2002). Thioalkalivibrio thiocyanoxidans sp. nov. and Thioalkalivibrio paradoxus sp. nov., novel alkaliphilic, obligately autotrophic, sulfur-oxidizing bacteria capable of growth on thiocyanate, from soda lakes. Int. J. Syst. Evol. Microbiol. 52, 657-664. doi: 10.1099/00207713-52-2-657

Sorokin, D. Y., Tourova, T. P., Sjollema, K. A., and Kuenen, J. G. (2003). Thialkalivibrio nitratireducens sp. nov., a nitrate-reducing member of an autotrophic denitrifying consortium from a soda lake. Int. J. Syst. Evol. Microbiol. 53, 1779-1783. doi: 10.1099/ijs.0.02615-0

Tabita, F. R., Hanson, T. E., Li, H., Satagopan, S., Singh, J., and Chan, S. (2007). Function, structure, and evolution of the RubisCO-like proteins and their RubisCO homologs. Microbiol. Mol. Biol. Rev. 71, 576-599. doi: 10.1128/ MMBR.00015-07

Tamura, K., Stecher, G., Peterson, D., Filipski, A., and Kumar, S. (2013). MEGA6: molecular evolutionary genetics analysis version 6.0. Mol. Biol. Evol. 30, 27252729. doi: 10.1093/molbev/mst197

Thorvaldsdóttir, H., Robinson, J. T., and Mesirov, J. P. (2013). Integrative Genomics Viewer (IGV): high-performance genomics data visualization and exploration. Brief. Bioinform. 14, 178-192. doi: 10.1093/bib/bbs017 
Tian, H.-F., Feng, J.-M., and Wen, J.-F. (2012). The evolution of cardiolipin biosynthesis and maturation pathways and its implications for the evolution of eukaryotes. BMC Evol. Biol. 12:32. doi: 10.1186/1471-2148-12-32

Tourova, T. P., Spiridonova, E. M., Berg, I. A., Slobodova, N. V., Boulygina, E. S., and Sorokin, D. Y. (2007). Phylogeny and evolution of the family Ectothiorhodospiraceae based on comparison of 16S rRNA, cbbL and nifH gene sequences. Int. J. Syst. Evol. Microbiol. 57, 2387-2398. doi: 10.1099/ijs. $0.65041-0$

Tsallagov, S. I., Tikhonova, T. V., Sorokin, D. Y., Kletzin, A., and Popov, V. O. (2015). “"Thiocyanate dehydrogenase” is a novel copper enzyme of the primary thiocyanate degradation in haloalkaliphilic sulfur-oxidizing bacterium Thioalkalivibrio paradoxus ARh1," in Proceedings of the EMBO Workshop on Microbial Sulfur Metabolism, Helsingør, 52.

Watts, M. P., and Moreau, J. W. (2016). New insights into the genetic and metabolic diversity of thiocyanate-degrading microbial consortia. Appl. Microbiol. Biotechnol. 100, 1101-1108. doi: 10.1007/s00253-0157161-5

Wood, A. P., Kelly, D. P., McDonald, I. R., Jordan, S. L., Morgan, T. D., Khan, S., et al. (1998). A novel pink-pigmented facultative methylotroph, Methylobacterium thiocyanatum sp. nov., capable of growth on thiocyanate or cyanate as sole nitrogen sources. Arch. Microbiol. 169, 148-158. doi: 10.1007/ s002030050554

Youatt, J. B. (1954). Studies on the metabolism of Thiobacillus thiocyanoxidans. J. Gen. Microbiol. 11, 139-149. doi: 10.1099/00221287-11-2-139

Ziegler, C., Bremer, E., and Krämer, R. (2010). The BCCT family of carriers: from physiology to crystal structure. Mol. Microbiol. 78, 13-34. doi: 10.1111/j.13652958.2010.07332.x

Zumft, W. G. (1997). Cell biology and molecular basis of denitrification. Microbiol. Mol. Biol. Rev. 61, 533-616.

Conflict of Interest Statement: The authors declare that the research was conducted in the absence of any commercial or financial relationships that could be construed as a potential conflict of interest.

Copyright (c) 2017 Berben, Overmars, Sorokin and Muyzer. This is an open-access article distributed under the terms of the Creative Commons Attribution License (CC BY). The use, distribution or reproduction in other forums is permitted, provided the original author(s) or licensor are credited and that the original publication in this journal is cited, in accordance with accepted academic practice. No use, distribution or reproduction is permitted which does not comply with these terms. 